\title{
Bioorthogonal cycloadditions with sub-millisecond intermediates
}

\author{
Yujia Qing, Gökçe Su Pulcu, Nicholas A. W. Bell and Hagan Bayley*
}

\begin{abstract}
Tetrazine- and sydnone-based click chemistries have emerged as important bioconjugation strategies with fast kinetics and $\mathrm{N}_{2}$ or $\mathrm{CO}_{2}$ as the only by-product. Mechanistic studies of these reactions have focused on the initial rate-determining cycloaddition steps. The subsequent $\mathrm{N}_{2}$ or $\mathrm{CO}_{2}$ release from the bicyclic intermediates has been approached mainly through computational studies, which have predicted lifetimes of femtoseconds. In the present study, bioorthogonal cycloadditions involving $\mathrm{N}_{2}$ or $\mathrm{CO}_{2}$ extrusion have been examined experimentally at the single-molecule level by using a protein nanoreactor. At the resolution of this approach, the reactions appeared to occur in a single step, which places an upper limit on the lifetimes of the intermediates of $\sim 80 \mu \mathrm{s}$, consistent with the computational work.
\end{abstract}

Bioorthogonal click chemistry has emerged as a vital tool in chemical biology. The development of highly selective reactions, which proceed in an aqueous environment in near-quantitative yield, and involve reagents that are inert towards naturally occurring functional groups, has enabled scientists to realise a wide range of applications. ${ }^{[1-3]}$ For example, click chemistry is invaluable for forming conjugates with and between biomacromolecules.

A widely-used bioorthogonal chemistry is based on cycloadditions between tetrazines and dienophiles, often referred to as inverse-electron demand Diels-Alder (iEDDA) reactions. ${ }^{[4]}$ A good match between the LUMO $_{\text {tetrazine }}$ and $\mathrm{HOMO}_{\text {dienophile }}$ endows tetrazine-based iEDDA reactions with fast bimolecular kinetics compared to other click reactions. The rate constants are as high as $10^{6} \mathrm{M}^{-1} \mathrm{~s}^{-1}$ under physiological conditions $^{[5]}$. The proposed mechanism for tetrazine-based iEDDA involves an initial cycloaddition to form a bicyclic intermediate, followed by a retro-cycloaddition step in which a molecule of $\mathrm{N}_{2}$ is extruded to yield a 4,5-dihydropyridazine (Figure 1a). For cyclooctene dienophiles, slow tautomerisation ensues in protic solvents to yield the 1,4-dihydro-isomer. ${ }^{[6,7]}$ Recently, another class of bioorthogonal click reaction, between sydnones and strained alkynes, has been developed. This reaction also proceeds through a cycloaddition/retrocycloaddition pathway, but it is slower $\left(\sim 1 \mathrm{M}^{-1} \mathrm{~s}^{-1}\right) \cdot{ }^{[8,9]}$ In this case, $\mathrm{CO}_{2}$ is released during the retro-cyclization step (Figure $1 \mathrm{~b}$ ).

There has been considerable interest in the development of improved bioorthogonal reaction pairs by acceleration of the rate-limiting cycloaddition step. Manipulation of the conformational strain of dienophiles ${ }^{[5,6,10]}$ and the electronic properties of tetrazines ${ }^{[11,12]}$ have achieved positive outcomes, which are supported by computational results ${ }^{[13,14]}$. For example fusion of the eight-membered ring of trans-cyclooctene with a

[*] Y. Qing, Dr. G. S. Pulcu, Dr. N. Bell, Prof. H. Bayley Department of Chemistry University of Oxford

Chemistry Research Laboratory, 12 Mansfield Road, Oxford, OX1 3TA (U.K.)

E-mail: hagan.bayley@chem.ox.ac.uk

Supporting information for this article is given via a link at the end of the document. cyclopropane ring accelerated the rate of tetrazine addition by 27-fold. ${ }^{[6]}$ In contrast, research into the dynamics of $\mathrm{N}_{2}$ and $\mathrm{CO}_{2}$ release, which yield the final products, has been largely limited to computational studies, ${ }^{[15]}$ most likely because the intermediates are predicted to be too short-lived to observe by approaches such as stopped-flow spectroscopy $(\sim 1 \mathrm{~ms}$ resolution). Indeed, quantum mechanical (QM) and quasiclassical trajectory (QCT) simulations with simplified reactants in the gas phase have suggested that the barrier to $\mathrm{N}_{2}$ and $\mathrm{CO}_{2}$ loss is low and that the bicyclic adducts have lifetimes of the order of a C-C bond vibration ( $60 \mathrm{fs}) \cdot{ }^{[9,15]}$
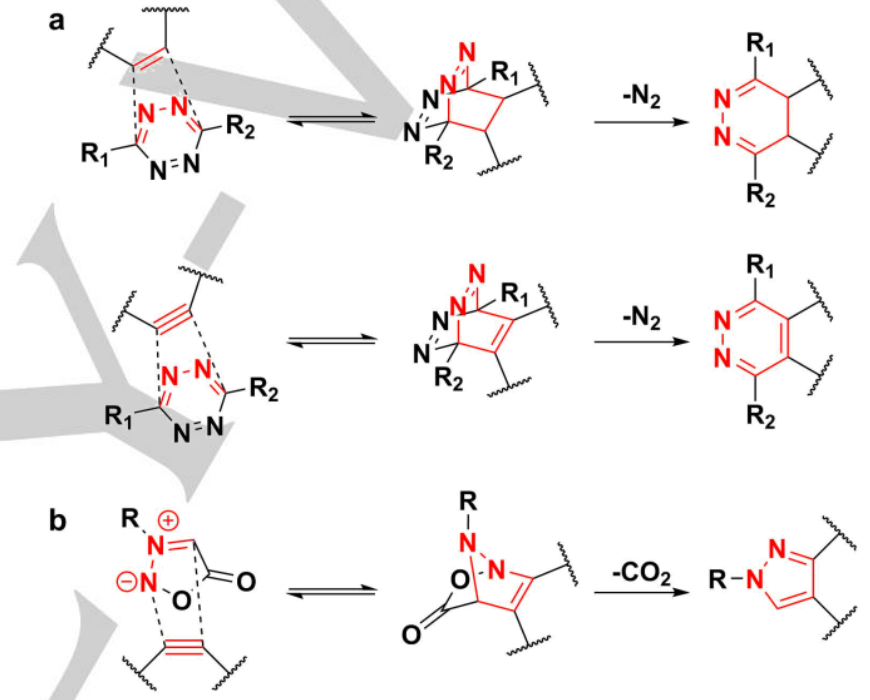

Figure 1. Cycloadditions that release $\mathbf{N}_{2}$ or $\mathbf{C O}_{2}$. a) iEDDA reactions between a tetrazine and a strained alkene or alkyne. For the alkene, the subsequent 1,3-prototropic isomerisation step leading to the 1,4dihydropyridazine is omitted here, because the rate is too slow to be detected by the nanoreactor approach. ${ }^{[6,7]}$ b) Cycloaddition between a sydnone and a strained alkyne.

Challenged by the computational studies, we set out to seek intermediates for these cycloadditions by our nanoreactor approach, in which individual reactions are carried out within the $\alpha$-hemolysin $(\alpha \mathrm{HL})$ protein pore in aqueous solution and monitored in real time by ionic current recording ${ }^{[16]}$. An internal residue within the transmembrane $\beta$ barrel of the $\alpha \mathrm{HL}$ pore is modified with a reactant of interest. Changes in the mass, shape or polarity of the attached reactant, caused by bond-making and bond-breaking reactions, or isomerisations, alter ion flow, and cause a change in the recorded current (Figure 2). The singlemolecule approach reveals transient intermediates, even in steps that are not rate-limiting. ${ }^{[17-20]}$ The time resolution of the approach is limited by instrument noise to the microsecond domain. ${ }^{[21,22]}$ In the set-up used in the present work, we expect to have a $>90 \%$ chance of "seeing" a bicyclic intermediate in a single experiment if its lifetime is $80 \mu \mathrm{s}$, and its formation and disappearance are associated with current steps of $5 \mathrm{pA}$ (see Supporting Information). 
Another advantage of the nanoreactor approach is that the reaction conditions can closely resemble the environment required for bioconjugation. Here we examine chemistry near a protein surface, in aqueous solution, at neutral $\mathrm{pH}$ and at room temperature. Unlike in silico simulations, the reagents used to perform nanoreactor experiments contain obligatory handles for labelling reactions, enabling direct comparison with the complex scaffolds used in biological applications.
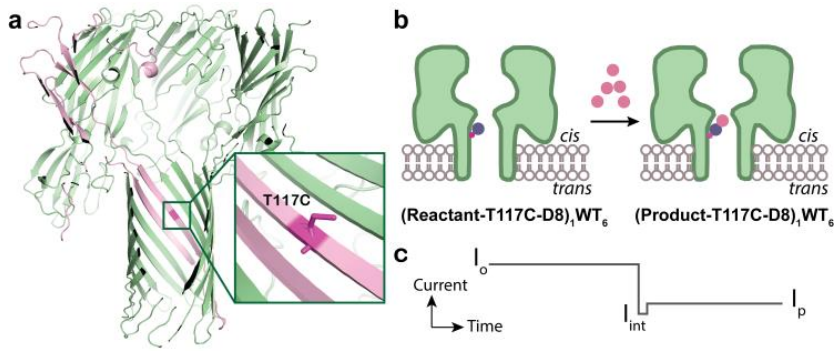

Figure 2. An engineered nanoreactor for single-molecule chemistry. a) Structure of the $\alpha \mathrm{HL}$ heteroheptamer used in this work, which contains a single cysteine residue (magenta) at position 117 in one of the seven subunits. b) The heteroheptamer containing one cysteine is modified with a first reactant (purple). The second reactant (pink) is added into the trans solution. Product formation is monitored by ionic current recording. c) Idealised current-time trace showing the expected levels for the open pore $\left(I_{0}\right)$, an intermediate (lint), and the product (IP).

To observe bimolecular click chemistry at the singlemolecule level, the $\alpha \mathrm{HL}$ pore was first modified with one of the reactants. A single cysteine residue has previously been introduced at position 117 within one of the seven $\alpha \mathrm{HL}$ subunits. ${ }^{[17]}$ The side-chain thiol projects into the lumen of the $\beta$ barrel, and in the present work reactive groups were introduced into this $\alpha \mathrm{HL}$ construct by Michael addition with various maleimide derivatives (Figure 2, 3a).

For iEDDA reactions involving tetrazines, the "diene" 6methyl-tetrazine $(\mathrm{mTz})$ or the dienophile trans-cyclooctene (TCO) was attached within the $\alpha \mathrm{HL}$ pore to create the nanoreactors (mTz-T117C-D8) ${ }_{1} \mathrm{WT}_{6}$ and (TCO-T117C-D8) ${ }_{1} \mathrm{WT}_{6}$. To examine the reaction of a sydnone with a strained alkyne, the $\alpha \mathrm{HL}$ pore was functionalised with a dibenzocyclooctyne (DBCO) to give (DBCO-T117C-D8) ${ }_{1} \mathrm{WT}_{6}$. After a modified pore had inserted into a lipid bilayer, the open-pore current level was recorded at $+50 \mathrm{mV}$ in $2 \mathrm{M} \mathrm{KCl}, 10 \mathrm{mM}$ MOPS, $10 \mu \mathrm{M}$ EDTA, pH 7.4. The unitary conductance values were: unmodified (T117CD8) ${ }_{1} \mathrm{WT}_{6}, 1.66 \pm 0.06 \mathrm{nS}$; (TCO-T117C-D8) ${ }_{1} \mathrm{WT}_{6}, 1.19 \pm 0.06 \mathrm{nS}$ (28\% reduction over the unmodified protein); $\mathrm{mTz}-\mathrm{T} 117 \mathrm{C}$ $\mathrm{D} 8){ }_{1} \mathrm{WT}_{6}, 1.02 \pm 0.10 \mathrm{nS}$ (38\% reduction); (DBCO-T117CD8) ${ }_{1} \mathrm{WT}_{6}, 1.46 \pm 0.09 \mathrm{nS}$ (12\% reduction).

The addition of a reaction partner to the trans compartment resulted in an additional current blockade $(\Delta \mathrm{l})$ after a waiting time $(\tau)$ for all 5 combinations of reactants tested (Figure $3 b$ ). Given sufficient individual determinations of $\tau$ (e.g. $n=20$ ), the mean waiting time $<\tau>$ can be used to determine the bimolecular rate constant, which was carried for (mTz-T117C-D8) ${ }_{1} \mathrm{WT}_{6}$ and the rel-(1R,4E,pR)-cyclooct-4-enol (TCO-OH) (see below). The current step was absent when the wild-type $\alpha \mathrm{HL}$ pore or unmodified (T117C-D8) ${ }_{1} \mathrm{WT}_{6}$ was used. Neither reversal of the applied potential nor prolongation of the recording time $(>2 \mathrm{~h})$ resulted in reversal of the conductance decrease, indicating that an irreversible reaction had occurred at the reactive site within the pore. No additional current steps were revealed under these conditions, or at $\mathrm{pH} 6.0$ or $\mathrm{pH} 8.5$, suggesting that the reactions either occur in a single step or through a transient (undetected) intermediate.

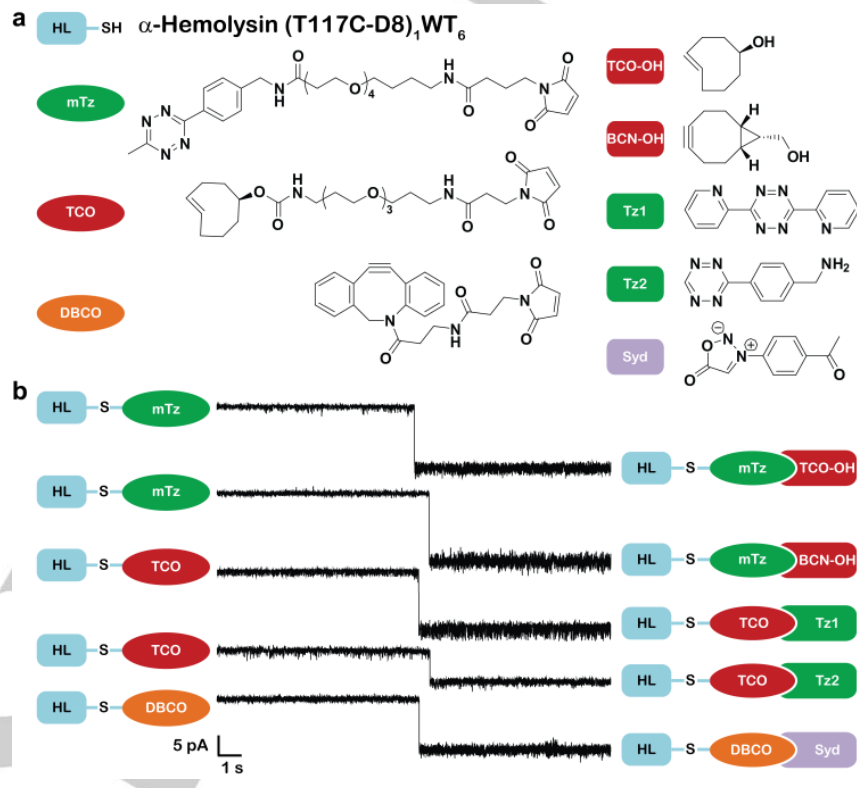

Figure 3. Single-channel recordings for bioorthogonal cycloadditions. a) Structures of the reagents used to modify Cys-117 within lumen of the nanoreactor (left) and the reactants (right) added to the trans compartment of the bilayer apparatus. b) Current traces showing various cycloaddition reactions. The buffer was $2 \mathrm{M} \mathrm{KCl}, 10 \mathrm{mM}$ MOPS, pH 7.4, $10 \mu \mathrm{M}$ EDTA. The temperature was $5^{\circ} \mathrm{C}$ for the top trace and room temperature $\left(22 \pm 1^{\circ} \mathrm{C}\right)$ for the remaining traces. Note the increase in noise after the cycloaddition reaction.

Table 1. Amplitude change $(\Delta \mathrm{I})$ and noise change ( $\left.\Delta \mathrm{I}_{\mathrm{RMS}}\right)$ after cycloadditions within the $\alpha \mathrm{HL}$ nanoreactor.

\begin{tabular}{|c|c|c|c|c|}
\hline $\begin{array}{c}\text { Modifica } \\
\text { tions }^{[a]}\end{array}$ & Reactants $^{[\mathrm{b}]}$ & $\Delta \mathrm{l} / \mathrm{pA}$ & $\Delta \mathrm{l}_{\mathrm{RMS}} / \mathrm{pA}$ & Repeats \\
\hline \multirow[t]{6}{*}{$\mathrm{mTz}$} & $\begin{array}{l}\text { rel-(1R,4E,pR)- } \\
\text { cyclooct-4-enol }\end{array}$ & $11.0 \pm 3.0$ & $0.15 \pm 0.07$ & 22 \\
\hline & (a trans-cyclooctene) & & & \\
\hline & $(\mathrm{TCO}-\mathrm{OH})$ & & & \\
\hline & $\begin{array}{l}\text { bicyclo[6.1.0]non-4-yn- } \\
\text { 9-ylmethanol }\end{array}$ & $12.5 \pm 2.0$ & $0.27 \pm 0.11$ & 8 \\
\hline & (a strained alkyne) & & & \\
\hline & $(\mathrm{BCN}-\mathrm{OH})$ & & & \\
\hline \multirow[t]{4}{*}{ TCO } & $\begin{array}{l}\text { 3,6-di-2-pyridyl-1,2,4,5- } \\
\text { tetrazine }\end{array}$ & $13.4 \pm 1.8$ & $0.36 \pm 0.13$ & 6 \\
\hline & $(T z 1)$ & & & \\
\hline & $\begin{array}{l}\text { 3-phenyl-1,2,4,5- } \\
\text { tetrazine }\end{array}$ & $9.4 \pm 2.0$ & $0.09 \pm 0.02$ & 5 \\
\hline & $(\mathrm{Tz2})$ & & & \\
\hline \multirow[t]{2}{*}{ DBCO } & $\begin{array}{l}\text { 3-(4-acetyl- } \\
\text { phenyl)sydnone }\end{array}$ & $12.0 \pm 4.0$ & $0.21 \pm 0.10$ & 5 \\
\hline & (Syd) & & & \\
\hline
\end{tabular}


[a] The $\alpha \mathrm{HL}$ heteroheptamer (Figure 2) was modified to incorporate one of three functionalities: 6-methyl-tetrazine (mTz), trans-cyclooctene (TCO), and dibenzocyclooctyne (DBCO) (Figure 3). [b] Reactants were added to the trans compartment. Subsequent cycloaddition led to a reduction in the current and an increase in root-mean-square current noise. Conditions: $2 \mathrm{M} \mathrm{KCl}, 10 \mathrm{mM}$ MOPS, $\mathrm{pH} 7.4,10 \mu \mathrm{M}$ EDTA at room temperature $\left(22 \pm 1^{\circ} \mathrm{C}\right)$.

The reduced current after each reaction was accompanied by increased root-mean-square noise (I $\mathrm{I}_{\text {RMS }}$ ) (Table 1, Figure S2), which most likely arises from movement of the reaction product inside the pore. Such noise has been observed previously when a disulfide-bonded polymer grows within a nanopore ${ }^{[23]}$, or when molecules such as poly(ethylene glycol) ${ }^{[24]}$ and $\mathrm{DNA}^{[25,26]}$ are tethered within a pore. No significant correlation was found between the molecular mass of the reactant and $\Delta \mathrm{l}$ or $\Delta \mathrm{l}_{\mathrm{RMS}}$, which depend on additional factors including the shape, polarity and flexibility of the modified side-chain. ${ }^{[16]}$

Previously, it has been shown that the release of $\mathrm{CO}_{2}$ from a carbamic acid in the $\alpha \mathrm{HL}$ nanoreactor causes a $5 \mathrm{pA}$ change in current $(\Delta \mathrm{l})$ at $-50 \mathrm{mV}$ in $2 \mathrm{M} \mathrm{KCl}{ }^{[17]} \mathrm{A}$ similar $\Delta \mathrm{l}$ value might therefore be expected for the $\mathrm{N}_{2}$ or $\mathrm{CO}_{2}$ extrusion steps in the cycloadditions examined here. Based on the experimental noise level, the optimal recording conditions for the detection of $\mathrm{N}_{2}$ or $\mathrm{CO}_{2}$ extrusion were determined to be a sampling frequency of $25 \mathrm{kHz}$ and a filter frequency of $5 \mathrm{kHz}$. A 4-pole Bessel filter was used with a $10-90 \%$ rise time of $70 \mu$ s at $5 \mathrm{kHz}$. Simulations of individual experiments showed that under these conditions intermediates with a $5 \mathrm{pA}$ current step and lifetimes of $40 \mu \mathrm{s}, 80$ $\mu$ s and $120 \mu$ s are detected in $23 \%, 94 \%$ and $100 \%$ of the current traces with a $3 \sigma$ signal-to-noise threshold for detection (see Supporting Information). For multiple experiments (Table 1), the chance of detecting an intermediate would be still greater.

Reaction pairs involving variously substituted dienes and strained dienophiles have been tested (Table 1, Figure 3). No intermediate species were observed in any case, in multiple experiments ( $n \geq 5$, Table 1, Figure S3). Therefore, the lifetimes of the bicyclic intermediates must be shorter than the $\sim 80 \mu \mathrm{s}$ detection limit of our experiments. Observation of the reaction between (mTz-T117C-D8) ${ }_{1} \mathrm{WT}_{6}$ and $\mathrm{TCO}-\mathrm{OH}$ at the lower temperature of $5^{\circ} \mathrm{C}$ gave a similar single-step decrease in current. Previously, nanopore interrogation of chemical reactions has reverealed intermediates in at least nine cases (Table S4). Events of microsecond duration $(5-100 \mu \mathrm{s})$ were also revealed in the current traces for interactions between polymers and the $\alpha \mathrm{HL}$ pore. ${ }^{[27]}$

Houk's group has investigated the loss of $\mathrm{N}_{2}$ during iEDDA reactions of tetrazines by using $\mathrm{QM}$ and QCT simulations. ${ }^{[15]}$ Their theoretical results show that a fraction of the bicyclic intermediates with shorter lifetimes than the vibration of the C-C bonds ( $\sim 60 \mathrm{fs})$ formed during the cycloadditions is bypassed dynamically and the reaction is concerted. The authors conclude that the intermediates (fully formed and bypassed) have subpicosecond scale mean lifetimes, about five orders of magnitude below our detection limit. However, the simulations were done in the gas phase, in the absence of collisional relaxation imparted by solvent molecules. The lifetimes of the bicyclic intermediates in the condensed phase remain a question for theoretical chemists to address. Our results provide an experimental upper limit for their values.
For the reactions between (mTz-T117C-D8) ${ }_{1} \mathrm{WT}_{6}$ and TCO$\mathrm{OH}$, the waiting time before reaction has a mean value $\langle\tau>$ of $164 \pm 20 \mathrm{~ms}(\mathrm{n}=20)$ at $22 \pm 1^{\circ} \mathrm{C}$, yielding a bimolecular rate constant $(k)$ of $14 \mathrm{M}^{-1} \mathrm{~s}^{-1}$, where $k=1 /(<\tau>[\mathrm{TCO}-\mathrm{OH}])$ (Figure $\mathrm{S} 5)$. Values for similar reactions in the literature range from 80 to $800 \mathrm{M}^{-1} \mathrm{~s}^{-1} .{ }^{[11,28]}$ For the remaining reactions, the rate constants are also estimated to fall within one order of magnitude of the reported values (Table S3). Indeed, it has been shown that a rate constant determined in a nanoreactor can be up to one order of magnitude lower than the values in bulk solution. ${ }^{[19]}$ The difference has been attributed to the need for the free reactant to find the correct orientation for reaction within a confined space. Our single-molecule approach, with the necesary repeats, has value then for the determination of the overall rate constants for cycloaddition reactions under conditions realistic for bioconjugation.

In conclusion, bioorthogonal cycloaddition chemistry was observed for the first time at the single-molecule level at a protein surface in aqueous solution. The two types of reaction, tetrazine-based iEDDA and sydnone-strained alkyne cycloaddition, were chosen for their similarities in mechanism but distinct extrusion products, $\mathrm{N}_{2}$ and $\mathrm{CO}_{2}$. All five cycloaddition reactions examined displayed no intermediates longer lived than $\sim 80 \mu \mathrm{s}(94 \%$ certainty in a single experiment; Table 1, Figure 3). The upper limit on the lifetime of the intermediates, which we have determined, provides a reference point for future computational studies on bioorthogonal cycloadditions in solution.

\section{Acknowledgements}

This work was supported by a European Research Council Advanced Grant. Y.Q. is the recipient of China Scholarship Council-University of Oxford Scholarship.

Keywords: Bioorthogonal Chemistry • Click Chemistry • Cycloaddition $\cdot$ Single-Molecule Chemistry

[1] D. M. Patterson, L. A. Nazarova, J. A. Prescher, ACS Chem. Biol. 2014, 9, 592-605.

[2] J. Li, P. R. Chen, Nat. Chem. Biol. 2016, 12, 129-137.

[3] F. Liu, Y. Liang, K. N. Houk, Acc. Chem. Res. 2017, 50, 2297-2308

[4] M. L. Blackman, M. Royzen, J. M. Fox, J. Am. Chem. Soc. 2008, 130, 13518-13519.

[5] A. Darko, S. Wallace, O. Dmitrenko, M. M. Machovina, R. A. Mehl, J. W. Chin, J. M. Fox, Chem. Sci. 2014, 5, 3770-3776.

[6] M. T. Taylor, M. L. Blackman, O. Dmitrenko, J. M. Fox, J. Am. Chem Soc. 2011, 133, 9646-9649.

[7] A. Vázquez, R. Dzijak, M. Dračínský, R. Rampmaier, S. J. Siegl, M. Vrabel, Angew. Chemie Int. Ed. 2017, 56, 1334-1337.

[8] S. Wallace, J. W. Chin, Chem. Sci. 2014, 5, 1742-1744.

[9] M. K. Narayanam, Y. Liang, K. N. Houk, J. M. Murphy, Chem. Sci. 2016, 7, 1257-1261.

[10] J. Dommerholt, S. Schmidt, R. Temming, L. J. A. Hendriks, F. P. J. T. Rutjes, J. C. M. van Hest, D. J. Lefeber, P. Friedl, F. L. van Delft, Angew. Chemie Int. Ed. 2010, 49, 9422-9425. 
M. R. Karver, R. Weissleder, S. A. Hilderbrand, Bioconjug. Chem. 2011, 22, 2263-2270.

[12] W. Chen, D. Wang, C. Dai, D. Hamelberg, B. Wang, Chem Commun. 2012, 48, 1736-1738.

[13]

J. A. Wagner, D. Mercadante, I. Nikić, E. A. Lemke, F. Gräter, Chem. - A Eur. J. 2015, 21, 12431-12435.

[14] F. Liu, R. S. Paton, S. Kim, Y. Liang, K. N. Houk, J. Am. Chem. Soc. 2013, 135, 15642-15649.

[15] L. Törk, G. Jiménez-Osés, C. Doubleday, F. Liu, K. N. Houk, J. Am. Chem. Soc. 2015, 137, 4749-4758.

[16] H. Bayley, T. Luchian, S.-H. Shin, M. B. Steffensen, in Single Mol. Nanotechnol. Springer Ser. Biophys. 12 (Eds.: R. Rigler, H. Vogel), Springer Berlin Heidelberg, Berlin, Heidelberg, 2008, pp. 251-277. T. Luchian, S.-H. Shin, H. Bayley, Angew. Chemie Int. Ed. 2003, 42 , 1926-1929.

[18] L.-S. Choi, H. Bayley, Angew. Chemie Int. Ed. 2012, 51, 7972-7976.

[19] J. Lee, H. Bayley, Proc. Natl. Acad. Sci. 2015, 112, 13768-13773.

[20] S. Lu, W.-W. Li, D. Rotem, E. Mikhailova, H. Bayley, Nat. Chem.
2010, 2, 921-928.

[21] M. Mayer, J. K. Kriebel, M. T. Tosteson, G. M. Whitesides, Biophys. J. 2003, 85, 2684-2695.

[22] G. Shapovalov, H. a Lester, J. Gen. Physiol. 2004, 124, 151-161.

[23] S.-H. Shin, H. Bayley, J. Am. Chem. Soc. 2005, 127, 10462-10463.

[24] S. Howorka, L. Movileanu, X. Lu, M. Magnon, S. Cheley, O. Braha, H. Bayley, J. Am. Chem. Soc. 2000, 122, 2411-2416.

[25] S. Howorka, L. Movileanu, O. Braha, H. Bayley, Proc. Natl. Acad. Sci. 2001, 98, 12996-13001.

[26] S. Howorka, S. Cheley, H. Bayley, Nat. Biotechnol. 2001, 19, 636639.

[27] L. Movileanu, H. Bayley, Proc. Natl. Acad. Sci. U. S. A. 2001, 98, 10137-10141.

[28] A. Vito, H. Alarabi, S. Czorny, O. Beiraghi, J. Kent, N. Janzen, A. R. Genady, S. A. Alkarmi, S. Rathmann, Z. Naperstkow, et al., PLoS One 2016, 11, e0167425. 


\section{Entry for the Table of Contents}

\section{COMMUNICATION}

A nanoreactor approach has been used to investigate tetrazine- and sydnone-based bioorthogonal cycloadditions at the single-molecule level. All reactions examined displayed no intermediate longer lived than $80 \mu \mathrm{s}$. For future computational studies on such chemistry in solution, the work provides an upper limit on the lifetimes of the bicyclic intermediates.

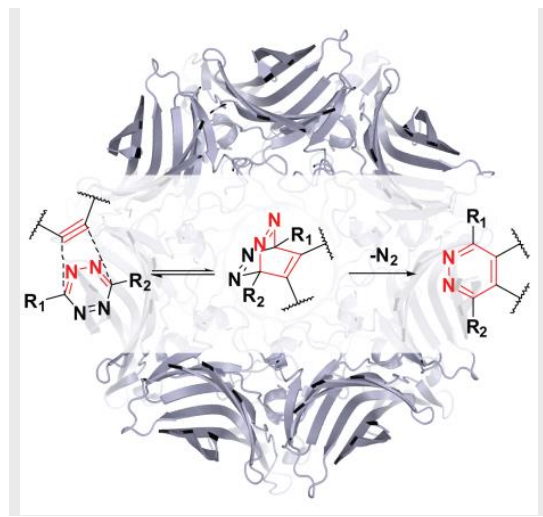

Yujia Qing, Gökçe Su Pulcu, Nicholas A. W. Bell and Hagan Bayley*

Bioorthogonal cycloadditions with sub-millisecond intermediates 